\title{
Facial and Hand Allotransplantation
}

\author{
Bohdan Pomahac ${ }^{1}$, Ryan M. Gobble ${ }^{1}$, and Stefan Schneeberger ${ }^{2,3}$ \\ ${ }^{1}$ Department of Surgery, Division of Plastic Surgery, Brigham and Women's Hospital, Harvard \\ Medical School, Boston, Massachusetts 02115 \\ ${ }^{2}$ Department of Visceral, Transplant and Thoracic Surgery, Innsbruck Medical University, Innsbruck, Austria \\ ${ }^{3}$ Department of Plastic and Reconstructive Surgery, Johns Hopkins University School of Medicine, \\ Baltimore, Maryland 21205 \\ Correspondence: bpomahac@partners.org
}

\begin{abstract}
Vascularized composite allotransplantation (VCA) is a novel therapeutic option for treatment of patients suffering from limb loss or severe facial disfigurement. To date, 72 hand and 19 facial transplantations have been performed worldwide. VCA in hand and facial transplantation is a complex procedure requiring a multidisciplinary team approach and extensive surgical planning. Despite good functional outcome, courses after hand and facial transplantation have been complicated by skin rejection. Long-term immunosuppression remains a necessity in VCA for allograft survival. To widen the scope of these quality-of-life-improving procedures, minimization of immunosuppression to limit risks and side effects is needed.
\end{abstract}

Vivallo scularized composite allotransplantation (VCA) is a novel therapeutic option for treatment of patients suffering from limb loss or severe disfigurement. According to the hand registry (www.handregistry.com) 41 hand transplantations have been performed worldwide. Of these, 21 were bilateral and 20 were unilateral transplantations. Overall graft survival and functional outcome are high, but diligent surgery together with carefully and individually adjusted immunosuppressive treatment, an intense rehabilitation protocol, and a high level of compliance and close patient follow-up is needed.

Since the first partial face transplant was performed in Amien, France by Drs. Dubernard and Devauchelle in 2005 (Devauchelle et al. 2006) a total of 19 face transplants (16 males, three females) have been reported in the literature. The largest number of transplants have been performed in France $(n=9)$ followed by the United States $(n=6)$, Spain $(n=3)$, and China $(n=1)$. Facial transplants were reported as partial transplants in 12 cases, near-total transplant in one case, and full transplants in six cases. Transplants incorporated osteomyocutaneous components in 12 cases and myocutaneous components in seven cases. The indication for transplantation included trauma in 15 cases (animal bite $n=3$, burn $=3$, ballistic $n=9$ ), congenital deformities in three cases, and tumor ablation in one case. To date, there have been two postoperative deaths, one of which occurred in a patient who had concomitant bilateral hand transplants and succumbed to postoperative complications and a second

Editors: Laurence A. Turka and Kathryn J. Wood

Additional Perspectives on Transplantation available at www.perspectivesinmedicine.org

Copyright (C) 2014 Cold Spring Harbor Laboratory Press; all rights reserved; doi: 10.1101/cshperspect.a015651

Cite this article as Cold Spring Harb Perspect Med 2014;4:a015651 
patient who was noncompliant with immunosuppressive therapy (Siemionow and Ozturk 2012). There have been no reported cases of graft loss, graft-versus-host disease, or hyperacute or chronic graft rejection.

Despite good functional outcome, courses after hand and face transplantation have been complicated by skin rejection (Schneeberger et al. 2009; Hautz et al. 2012a). Long-term immunosuppression remains a necessity in VCA for allograft survival. To widen the scope of these quality-of-life-improving procedures, minimization of immunosuppression to limit risks and side effects is needed.

\section{PREPARATION AND SURGICAL PROCEDURE}

In preparation for hand transplantation, the stumps of the recipients should be carefully assessed. Bone length, muscular, vascular, and nerve status can be analyzed using CT scan, angio-CT, angiography, magnetic resonance imaging, and ultrasound. This is to rule out a neuroma at a level far proximal to the amputation. Routine workup should include blood work, $\mathrm{X}$ rays, electrocardiography, echocardiography, and spirometry. For exclusion of comorbidities such as malignancies or infections patients undergo gastroscopy, colonoscopy, and dental and oropharyngeal examination (Brandacher et al. 2007).

Surgical strategies in hand transplantation have to be adapted to the level of amputation as well as the exact length and quality of structures in the recipient's stump. For each case a precise plan and in some cases development of novel reconstruction techniques are required (Schneeberger et al. 2011; Landin et al. 2012). At present, definite recommendations regarding the maximum duration of ischemia do not exist; however, ischemia time should be kept as short as possible and not exceed 10 hours. Although cold flush and preservation with histidine, tryptophan, ketoglutarat solution (HTK) or University of Wisconsin (UW) solution might limit myocyte damage, muscles are sensitive to ischemia and damage such as interstitial edema, microvascular constriction, and/ or damage of myocyte membranes may result in muscle dysfunction after $2.5 \mathrm{~h}$ of (warm) ischemia (Nanobashvili et al. 2003).

All anatomic structures such as tendons, nerves, and vessels are dissected under tourniquet control in the donor and recipient. After release of the tourniquet, the forearm is perfused with cold HTK solution through the brachial artery. Next, all structures are transected and osteotomies of the radius and ulna are performed. After wound closure the donor is fitted with cosmetic prostheses.

Hand allotransplantation is then performed under tourniquet control. After bone preparation and osteosynthesis, revascularization is initiated by anastomosis of one main artery and two veins followed by tendon/muscle repair and definitive vessel repair. Next, nerve repair is performed before skin closure. Alternatively, revascularization can be performed later after the extensor tendons are repaired and rapid anastomosis of one to two dorsal veins and nerve repair. Both radial and ulnar arteries are repaired next, followed by reconstruction of the remaining veins. This is followed by flexor tendon repair and skin closure (Azari et al. 2012).

Facial transplantation is a complex endeavor that requires a multidisciplinary approach encompassing the most cutting-edge aspects of plastic surgery, transplantation immunology, and anesthesia. As no two faces are the same, no two operations are exactly the same. There are, however, guiding principles that should be followed. Each operation requires an anastomosis to create arterial inflow and venous outflow. Also nerve coaptation is required for both motor and sensory branches. Arterial and venous anastomosis as well as nerve coaptation may be either unilateral or bilateral depending on the amount of tissue to be replaced. Osseous portions from the donor may be included in the composite tissue allograft.

Arterial inflow has been established through the external carotid artery, and its branches including the facial artery and the external maxillary artery, whereas venous outflow has been achieved via the facial vein, thyrolingual facial trunk, external and internal jugular vein, and the retromandibular vein. Arterial and ve- 
nous anastomoses are performed with the face flipped down onto the recipient's chest using a microsurgical technique. An end-to-end anastomosis is preferred whenever possible and is usually able to be performed given the similar caliber of donor and recipient vessel lumen as well as the ease in obtaining adequate length vessel length from the donor (Siemionow and Ozturk 2012). An end-to-side anastomosis between the right subclavian and the right common carotid arteries has been reported in a 42 yr-old male who underwent transplantation of $35 \%$ of the face including partial bilateral cheek, upper and lower lip, chin, tongue, and mandible (Cavadas et al. 2012).

Ultimately the choice of donor and recipient vessel inflow and outflow will depend on the tissues to be transplanted. It has been suggested that for reconstruction of tissues of the midface or upper face that the superficial temporal and facial vessels are preferred, whereas reconstruction of the lower face and mandible is best achieved by using the external carotid and its branches, and this would certainly seem to hold true for tissue allotransplantation (Takamatsu et al. 1996). When an osteomyocutaneous transplant is performed more proximal vessels are usually preferred (e.g., external carotid artery and facial artery); however, we have shown in a cadaver study that the facial artery itself is capable of maintaining perfusion to the entire midface, including the maxilla, anterior half of mandible from the masseter muscle insertion and zygoma (Pomahac et al. 2012b), as well as the total facial allograft including maxilla (Pomahac et al. 2012a).

Full transplants deserve particular attention with regard to inclusion of the superficial temporal vessels. Inclusion of these vessels requires inclusion of the parotid glands bilaterally, which results in unaesthetic fullness of the cheeks bilaterally unless a superficial parotidectomy is performed before transplantation, which significantly increases operative time. Including the parotid glands also limits facial nerve coaptation to the level of the trunk, as the branches of the donor facial nerve are inaccessible. We have developed a technique for full facial transplantation based on only the facial arteries, which al- lows for more target innervation of effector muscles without the unsightly bulges seen when the parotid gland is included (Pomahac et al. 2012b).

Most commonly, two arterial anastomoses and two or more venous anastomoses are performed; however, there is no definitive clinical or experimental evidence to support recommendations for which vessels should be used or how many anastomoses are required for each type of allotransplantation being performed. Given the high stakes of facial allotransplantation, one is better served to include more than one anastomosis when possible lest a single arterial or venous anastomosis become compromised risking loss of the entire graft. Also, given the nature of the recipient's vessels as most of these patients have undergone multiple prior operations and/or received prior radiation, it is wise to have a roadmap as to the nature and location of the recipient's vessels. As such, preoperative imaging including ultrasound and CT/MRI angiography should be obtained before operative intervention. Preoperative CT angiography is useful for identifying the best target vessels for vascular anastomoses thereby limiting operative time exploring unusable vessels. It can alert the surgical team for the potential need of vein grafts as a backup option if less than ideal vascular anatomy is identified preoperatively. The key aspects in choosing the ideal vessels are an optimal size match between recipient and donor vessels, an adequate amount of length between allograft pedicle and donor vessels, and accessibility of the pedicle (Soga et al. 2012). Magnetic resonance (MR) angiography may be particularly useful in both preoperative imaging with a large shrapnel component and/or postoperative follow-up once surgical plates have been introduced into the area. If temporal or parietal scalp need be included preservation of the transverse facial artery that connects the facial and superficial temporal arteries will provide adequate blood flow. If blood supply to these regions is not adequate dissection of the superficial temporal arteries in the superficial plane at the preauricular level may be performed for supercharging at the recipients corresponding location (Pomahac et al. 2012b). 
CT imaging is useful not only in planning intraoperative vascular anastomoses but also in planning for osteotomies in cases in which an osteomyocutaneous transplant is performed. Brown et al. has described a cadaveric study for full face transplant including double jaw and tongue using CT-assisted techniques when performing osteotomies on both the donor and recipient (Brown et al. 2012). In this study both the donor and recipient cadavers were placed in intramaxillary fixation. Three-dimensional reconstructions were then superimposed on donor and recipient skulls using surgical modeling software. Leforte III and sagittal split osteotomies were planed based on these projections. Stereolithographic models were produced and cutting guides for Leforte III osteotomies were made for use during the mock transplantation. Planned osteotomies were then imported into intraoperative navigation software and the Leforte III osteotomies were performed using this intraoperative guidance. CT scans performed after the mock transplantations showed that accurate skeletal fixation and occlusion was noted to be normal. Dr. Rodriguez and colleagues were then able to translate the experienced gained performing these mock transplantations to complete the first total face, double jaw, and tongue transplant in a 37-yr-old male who sustained a central face high energy avulsive ballistic injury (Dorafshar et al. 2013). Use of CT imaging to plan osteotomies during osteomyocutaneous facial transplantation will likely be incorporated into future allotransplantations to improve the accuracy of skeletal fixation and decrease operative times. Furthermore, use of CT imaging may help us more accurately predict which donors are more likely to result in an optimal skeletal match for facial transplant recipients. However, limitations in donor availability will prevent passing up eligible donors despite a less than ideal skeletal match for the foreseeable future.

Sensory nerves used in facial transplantation include the trigeminal nerve and its branches (e.g., infraorbital nerve, supraorbital nerve, mental nerve, buccal sensory nerve, lingual nerve, inferior alveolar nerve, and cervicofacial nerve). Direct nerve coaptation of both motor and sensory nerves using fine monofilament suture under microscopic magnification is the preferred method; however, in cases in which trauma has destroyed the recipient sensory nerves motor coaptation alone has been performed (Guo et al. 2008; Siemionow et al. 2009, 2010; Lantieri et al. 2011). Also, in cases in which the mental nerves are unable to be repaired directly the donor mental nerves have been placed in close approximation of the recipient mental foramen (Lantieri et al. 2008). The facial nerve serves as the motor input for facial transplantation. Coaptation of facial motor nerve branches at more distal sites allows for more retention of native nerve length decreasing the chances of developing synkinesia (Pomahac et al. 2012b). Nerve grafts can be used when adequate length is not available (e.g., thoracodorsal nerve, greater auricular nerve).

Inset of the graft is typically performed in a central-to-lateral and inferior-to-superior sequence. Osseous fixation is achieved using plates as screws customized to the particular bone being fixed. Liberal use of Mitek (Burnsville, $\mathrm{MN}$ ) anchors in different locations in the zygoma, supraorbital bar, and mandible are used for securing the tissues of the allograft to the underlying bony structure to provide some structure to the face and relieve tension on the vascular anastomoses (Pomahac et al. 2012b). It is essential to achieve watertight intraoral closure. The skin sutures are placed to promote the optimal facial contour and aesthetic outcome. Drains are placed as needed depending on the amount of tissue transplanted. At our institution we chose to also include a sentinel flap that can be used to monitor for rejection episodes. Sentinel flaps are placed at areas that require functional improvements. Rejection episodes were detected more accurately in the sentinel flap than in the facial allograft in two of our four face-transplant recipients (Pomahac et al. 2012a). The sentinel flap is less affected by confounding facial-skin conditions, including environmental exposure or from conditions such as dermatitis or rosacea, and is therefore felt to be more sensitive to rejection episodes (Saavedra et al. 2011). 


\section{OUTCOMES}

Sensitivity

Nerve regeneration after hand transplantation progresses rapidly with nerve endings reaching the fingertips at 6-9 months depending on the level of amputation/transplantation (Petruzzo et al. 2010; Hautz et al. 2011). Protective sensation returned in all and discriminative sensation in the majority of patients. The transplanted hands were incorporated into the patient's body image in almost all patients. Protective sensation is routinely achieved.

The outcome after forearm transplantation differs significantly from the outcome after hand transplantation (Schneeberger et al. 2011). Particularly the time course of return of function is significantly prolonged when compared with hand transplantation. The functional outcome, therefore, needs to be read in the light of inherit differences between hand and forearm transplantation. Overall, however, despite the postoperative course being significantly more challenging when compared with hand transplantation, forearm transplantation has also resulted in good patient satisfaction (Schneeberger et al. 2007, 2011). In addition to restoration of body integrity, improved motor function and movement control and fewer everyday challenges when compared with myoelectric prostheses have been achieved. The long and intense rehabilitation protocol and the slow return of function require thorough and cautious patient selection.

Restoration of sensation in facial allotransplantation has been assessed using several different quantitative sensory tests, including two-point discrimination, Semmes-Weinstein monofilaments, pressure-specified sensory devices, and heat and cold tolerance (Siemionow and Ozturk 2012). Restoration of light touch and temperature sensation has been shown to occur between 3 and 8 months in the majority of cases (Dubernard et al. 2007; Guo et al. 2008; Lantieri et al. 2008; Siemionow et al. 2009; Barret et al. 2011; Pomahac et al. 2012a). Light touch and sensation to the oral mucosa returns around 3 months, whereas thermal sensation does not typically return until 6-8 months posttransplantation. The rate of return of sensation is similar to that reported with innervated free flaps (Kimata et al. 1999). Documentation of sensory recovery has been reported even in cases in which direct sensory nerve coaptation was not possible secondary to trauma (Lantieri et al. 2008). This may be owing to interconnections between the trigeminal and facial nerve branches that may make direct nerve coaptation not entirely necessary (Baumel 1974; Tohma et al. 2004). Although sensory recovery has been noted in cases in which direct nerve coaptation was not possible we still recommend its performance in all facial transplants when possible.

Scarring of the recipient bed has a clear negative impact on sensory nerve regeneration, which will affect the ultimate outcome (Hermanson et al. 1987). Inclusion of skin within a free flap improves sensory recovery, whereas the presence of muscle and bone may act as a barrier for neurontinization from the recipient bed (Siemionow et al. 2011). Patients with thinner transplants, less transplanted tissues, and younger patients may have better sensory recovery (Lahteenmaki et al. 1991); however, more clinical data with facial transplantation needs to be accumulated before this will be known.

\section{Motor Function}

In hand transplantation, motor function returns almost immediately after transplantation. The patient's own forearm muscles enable finger movement, which continues to increase in range and strength over time. In many cases, the return of intrinsic hand muscle function can be observed and further enhances motor function. The majority of patients are able to perform all major tasks of daily living including holding small objects, turning pages and door knobs, writing, and returning to work (Petruzzo et al. 2010).

As mentioned above, the functional outcome after transplantation at more proximal levels requires prolonged rehabilitation and is overall less consistent (Landin et al. 2012). The functional return in these cases may continue to improve during the first 5 years after trans- 
plantation. Although reinnervation of intrinsic hand muscles has been observed in some cases, it cannot be routinely expected and the level of function is inferior when compared with hand transplantation. Protective but not discriminative sensation can be observed in the majority of these patients. Return of hand function after forearm transplantation requires approximately 5 years to completion, as it is dependent on reinnervation and reactivation of graft forearm muscles. Overall, hand function in forearm transplantation remains inferior when compared with hand transplantation because reinnervation and reactivation of intrinsic hand muscles are unlikely.

In cases in which the level of amputation is proximal to the elbow area, the long distance for nerve regeneration and recovery is a major pace-limiting factor. Only a few such cases have been performed and arm function in these cases is still improving at this point. Elbow function and extrinsic finger flexion and extension have been satisfactory but the final and overall functional outcome in arm transplantation can only be estimated at this point (Brandacher et al. 2009). More patients and long-term follow-up is needed to ultimately determine the degree of function that can be regained in arm transplantation.

In all facial transplantations reported thus far, motor recovery has occurred later and often to a lesser extent than sensory recovery. This is unfortunate, as motor recovery will likely contribute more to a functionally useful and aesthetic face. As motor recovery takes longer to occur and motor recovery has not been documented in each case we do not know exactly the full extent of motor recovery to be expected following facial allotransplantation. However, reports from several different investigators do paint a picture of the extent of motor recovery possible. Dubernard et al. (2007) showed that return of motor activity occurred at 3 months after transplantation followed by the ability to move the lower lip at 4 months. Their patient was able to bring the lips into apposition at 6 months and to have a full smile at 18 months. Furthermore, the patient was able to move their nose and chin at 1-year posttransplantation
(Dubernard et al. 2007). Lantieri et al. reported that their patient had no evidence of facial nerve reinnervation on electromyography at 3 months posttransplantation; however, at 1 year, there was documented evidence of reinnervation on electromyography (Lantieri et al. 2008). Siemionow et al. described an improvement in facial mimetics by 6 months posttransplantation as evidenced by symmetric smiling and upper lip occlusion; however, upper lip and lower eyelid movement were imperfect. By 1 year, the investigators noted almost complete motor recovery (Siemionow et al. 2009, 2010). Barrett et al. reported an ability to move the frontalis, zygomaticus, and upper orbicularis occuli muscles along with unrestricted masticatory movement; however, their patient was unable to close the eyes (Barret et al. 2011).

More recently we have reported on three patients who have undergone full facial transplantation (Pomahac et al. 2012a). All three patients recovered motor function of their face. Along with our first patient that received partial face transplant, three of four have an excellent symmetry (Figs. 1A,B, 2A,B, and 3A,B). One patient has an asymmetrical smile owing to previous injury of the recipient's facial nerve, perhaps owing to traction (Fig. 4A,B).

Lack of long-term follow-up in facial transplantation for both sensory and motor activity remains a problem. Other difficulties in monitoring for the return of motor activity remain an overall lack of reporting as well as no uniformity of measuring such progress. One investigator has suggested using electromyography and functional magnetic resonance imaging to monitor for facial nerve reanimation (Hui-Chou et al. 2010). Although these methods may become part of the standard for monitoring for motor recovery they are still untested in facial transplantation specifically, and, for now, physical examination will remain the gold standard.

\section{Peripheral Nerve Regeneration and Cortical Integration}

Sensory nerve recovery for free tissue reconstruction is greater in the face than for that of the trunk or lower extremities in both neuroti- 

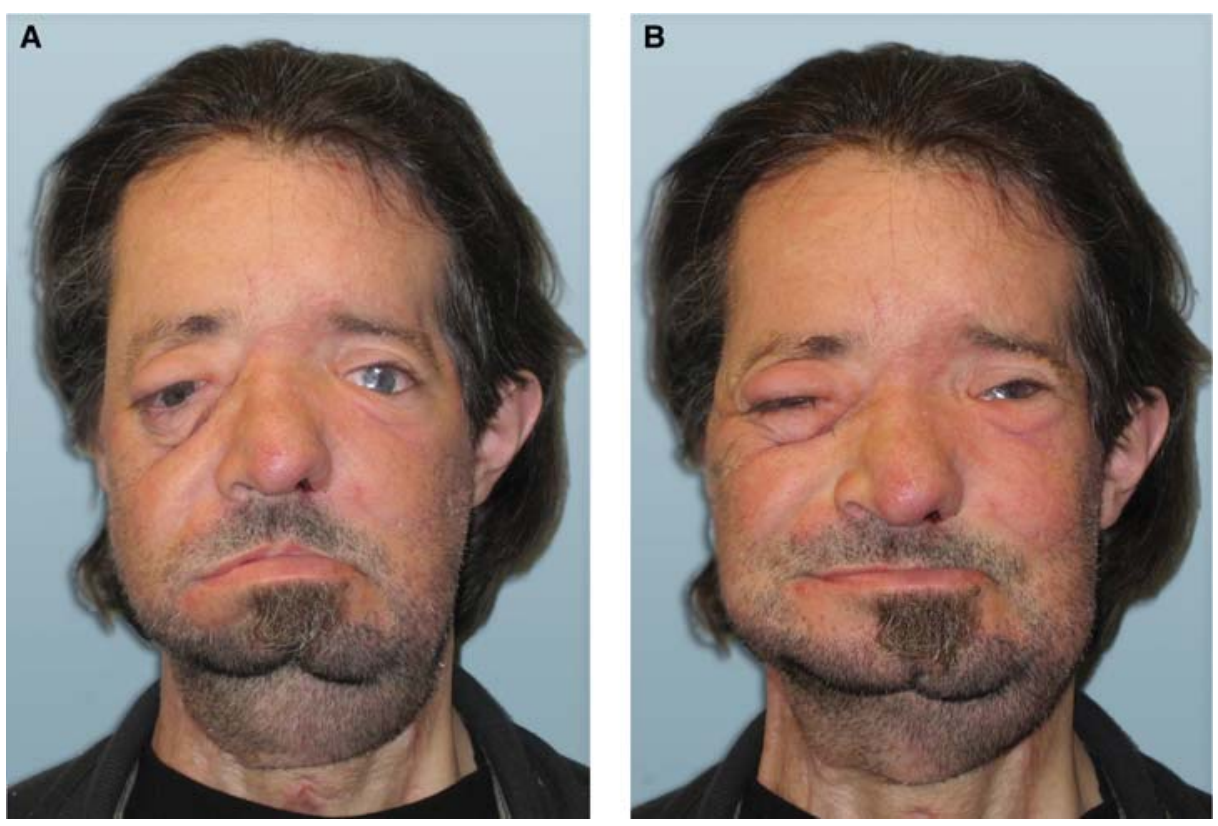

Figure 1. 26-yr-old male 12 months postfacial allotransplantation at rest $(A)$, and smiling $(B)$.
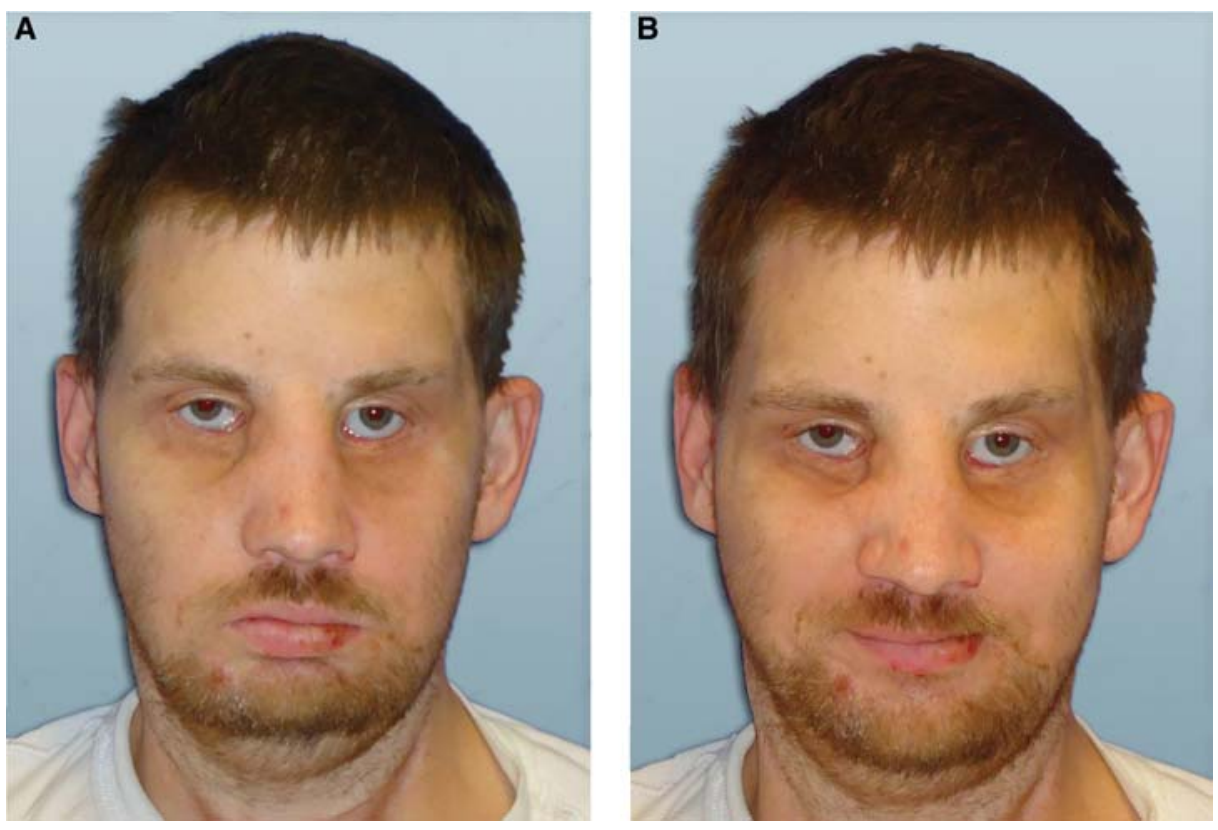

Figure 2. 31-yr-old male 12 months postfacial allotransplantation at rest $(A)$, and smiling $(B)$. 


\section{B. Pomahac et al.}
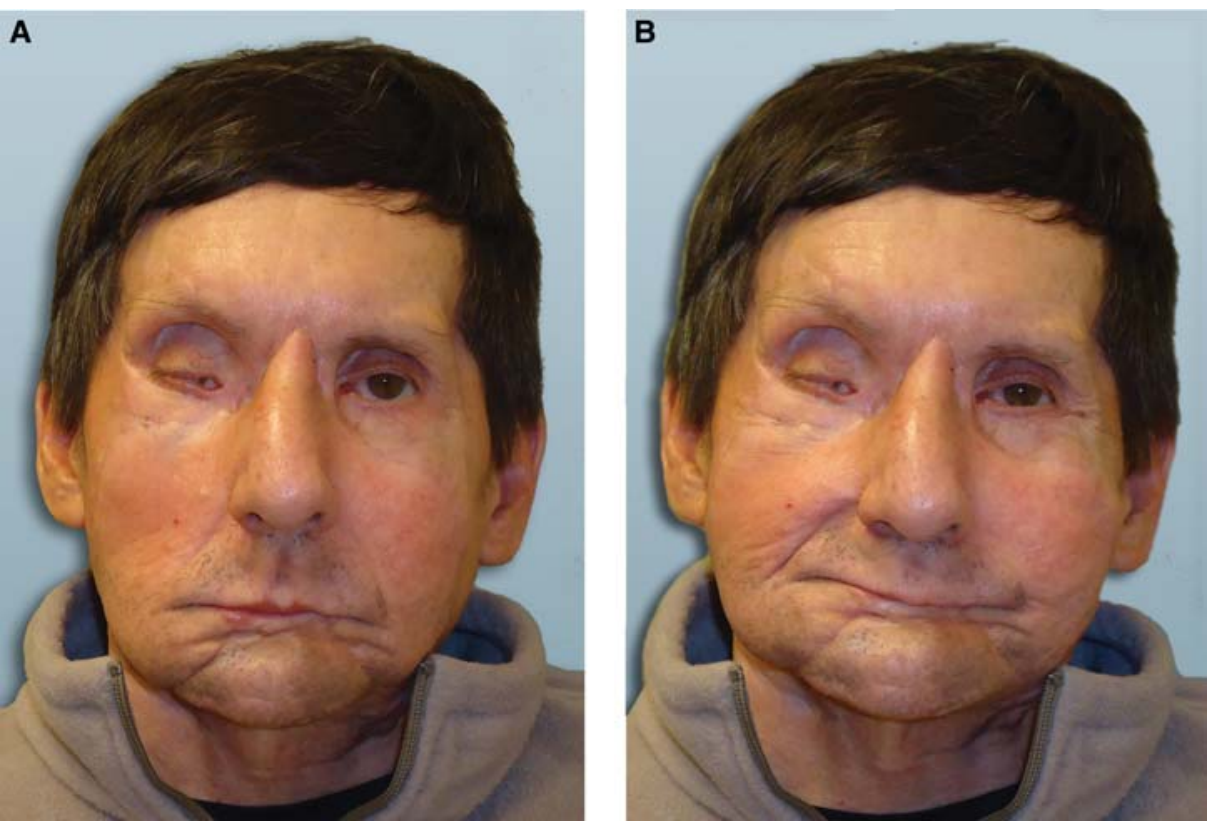

Figure 3. 62-yr-old male 36 months postfacial allotransplantation at rest $(A)$, and smiling $(B)$.
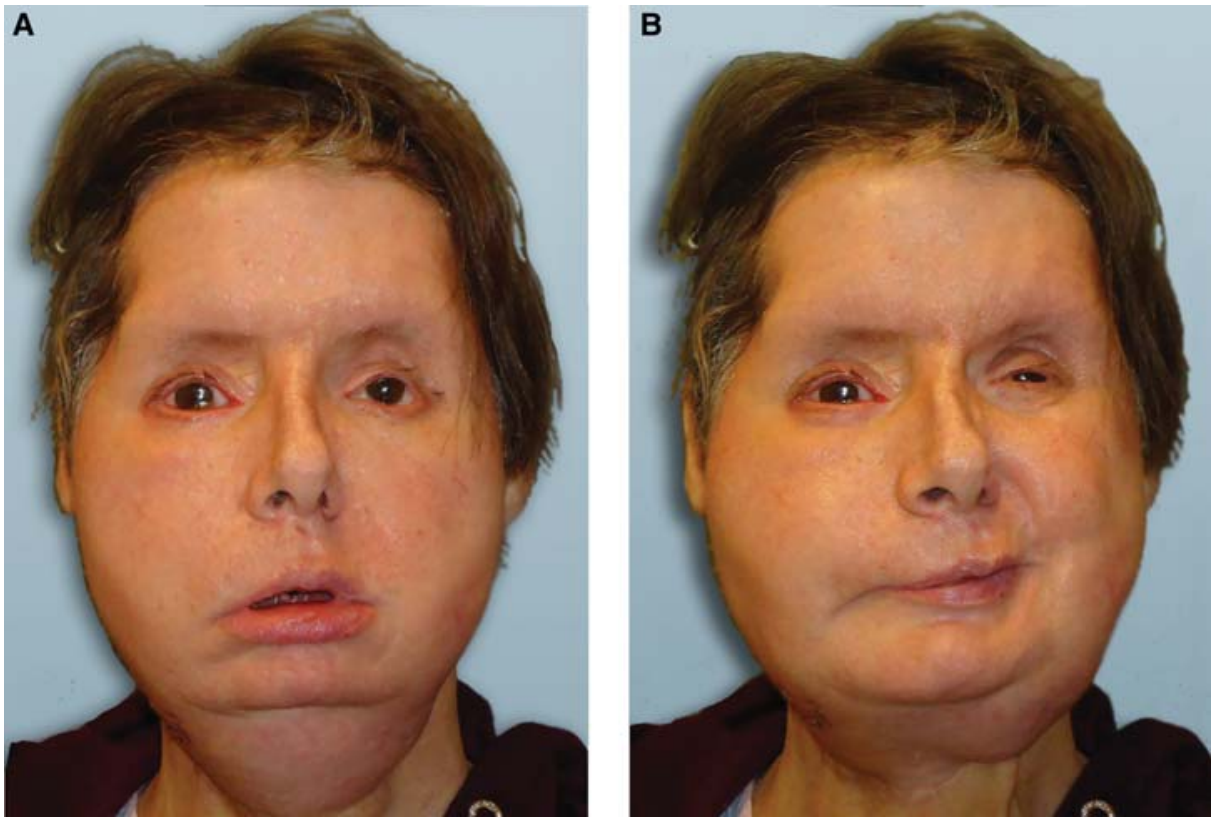

Figure 4. 58-yr-old female 12 months postfacial allotransplantation at rest $(A)$, and smiling $(B)$. 
nized and non-neurotinized flaps, which shows the greater cortical representation the face receives in the human homunculus (Lahteenmaki et al. 1991; Kuriakose, et al. 2001; Kerawala et al. 2006; Bianchi et al. 2010).

\section{Patient Satisfaction}

Patient satisfaction is of the utmost importance in every operation, but no more so than in facial allotransplantation. These patients submit themselves to a long operation followed by an even longer hospital stay and ultimately lifelong immunosuppression. For a successful outcome patient buy in is essential. As previously shown restoration of sensation takes many months, whereas return of motor activity can take over a year. Despite all of these obstacles patient satisfaction remains very high. Several investigators have noted restoration of olfaction and an ability to eat and drink within a week postoperatively (Dubernard, et al. 2007; Lantieri et al. 2008; Siemionow et al. 2009; Pomahac et al. 2012a). Patients who had been previously fed via gastrostomy tubes were able to have them removed and tracheostomy-dependent patients were able to be decanulated (Siemionow and Ozturk 2012). Furthermore, improvement in speech has been noted with transplantation of the hard palate and the use of an obturator (Siemionow et al. 2009; Pomahac et al. 2011).

Patient-specific questionnaire studies are yet to be performed, but most investigators report that their patients are happy with their outcomes. Results from a psychosocial analysis of quality-of-life measures using the MOS-SF-12 showed that patients at our institution who underwent facial allotransplantation had a significant improvement in their mental health in the 6 months posttransplantation (Chang and Pomahac 2012). Clearly for patients requiring facial transplantation the devastating nature of their injuries severely limits their ability to interact in society, and improvement both aesthetically and functionally is welcome. Ethical concerns remain, given the risk of death with the operation along with the risk of developing malignancy with the need for lifelong immunosuppression. Furthermore, access to care issues and an overall lack of donors make this life-altering procedure available only to a select group of patients.

\section{IMMUNOLOGICAL ASPECTS}

\section{Immunosuppression}

The immunology in VCA is characterized by the strong skin-directed immune response, the markedly different gravity of the immune response against the different tissues, and the ability to visually monitor the skin (Cendales et al. 2008; Hautz et al. 2012b). The failure of the first human hand transplantation reported in 1964 was caused by the strong immune response and the lack of modern immunosuppressive therapy (Gilbert 1964). Transplantation of the skin was considered impossible until hand and face transplantation was performed successfully after 1998. At this point, the side effects of long-term high-dose immunosuppression rather than rejection represents the remaining pacelimiting obstacle in this field (Hautz et al. 2010a; Brandacher et al. 2012). Two patients died following a combined hand and face transplantation and attempted bilateral upper and lower extremity transplantation (Lantieri et al. 2011; Daily Mail Reporter 2012). Rejection remains a challenge and threat, but the morbidity caused by the required drug treatment is limiting the larger-scale application of this nonlifesaving treatment. Concurrent with the advancements in solid organ transplantation, minimization or elimination of the need for long-term highdose and/or multidrug immunosuppression is the primary goal of global research in this novel field. A reduction of maintenance immunosuppression has recently been achieved in a small clinical trial. Such findings need to be confirmed and advanced in a larger group of patients (Schneeberger et al. 2013).

Facial transplants, along with hand transplants, are unique among transplant types in that they allow for direct visual observation of rejection episodes. They are also unique in that they possess very large amounts of skin, which is one of the most immunoreactive and antigenic tissues in the human body (Lee et al. 1991). 
Development of facial transplantation-specific protocols have adapted primarily from solid organ transplant protocols. Most centers use induction therapy with anti-interleukin 2 receptor antibodies (e.g., basiliximab, daclizumab) or antithymocyte globulins followed by a maintenance protocol that includes an antiproliferative agent (mycophenolatemofetil), a calcineurin inhibitor (tacrolimus), and a corticosteroid (prednisolone) (Siemionow and $\mathrm{Oz}-$ turk 2012). Donor origin stem cells have also been used to attempt to induce donor-specific tolerance via the development of a mixed allogeneic chimerism (Devauchelle et al. 2006; Dubernard et al. 2007). The goal of maintenance therapy is to avoid graft rejection, while at the same time reducing immunosuppression to limit the adverse events, which include infections and malignancy (van Leeuwen et al. 2010).

\section{Rejection Episodes}

One patient in the United States has lost a hand allograft as a consequence of arterial intimal hyperplasia on day 275 and one patient in France requested amputation following progressive rejection of the skin after stopping immunosuppression at 29 months (Petruzzo et al. 2010). Furthermore, several unconfirmed cases of hand loss have occurred in China. Although rejection in hand and face transplantation remains incompletely understood at this point, it appears that both the skin and the vasculature are important targets for the immune response in VCA. In some elements, the molecular mechanisms and dynamics of skin rejection are similar to other inflammatory skin conditions. T cells are recruited to the skin via activation of adhesion molecules, cytokines, and chemokines (Hautz et al. 2010b, 2012b). In addition to T-cell recruitment, ectopic lymphoid structures within the allograft associated with chronic rejection in solid organ transplantation might contribute to the strong alloimmune response toward the skin. In preclinical trials, molecules involved in cell trafficking in the skin have been successfully targeted to prevent rejection in VCA. In human hand transplantation, episodes of skin rejection have been observed in the vast majority of cases. Skin rejection was reversible in all patients compliant with immunosuppression and graft loss was prevented (Hautz et al. 2010a).

All patients who have $>1$ year follow-up after facial transplantation have experienced at least one episode of acute rejection, which manifests as cutaneous changes including skin swelling and erythema along with the development of nodules and/or papules. Furthermore, seven patients have experienced two acute rejection episodes and two developed three rejection episodes (Siemionow and Ozturk 2012). Acute rejections have all been confirmed histologically via skin and/or mucosal biopsy. Acute rejection episodes were successfully treated using treatment algorithms from solid organ rejection including the use of high-dose parenteral steroids and the adjustment of oral immunosuppressive therapy. Unique to facial transplantation is the ability to use phototherapy and the topical application of steroid and tacrolimus creams.

To date, there are also no documented cases of chronic rejection, again likely owing to the short follow-up, or graft-versus-host disease. In kidney and liver transplantation chronic rejection may occur anywhere from months to years posttransplantation and is characterized by fibrosis of the graft parenchyma (Seetharam et al. 2010). In cardiac transplantation, chronic rejection occurs over the same time course; however, it typically manifests itself as a vasculopathy that ultimately leads to loss of the graft (Kalache et al. 2011). As follow-up times in facial and hand allotransplantation are limited it is unclear yet whether chronic rejection will manifest with more fibrotic changes to the skin and subcutaneous tissues or with a vasculopathy of the transplanted vessels. Furthermore, we do not know exactly over what time course chronic rejection will occur although we would expect it to be similar to that seen in solid organ transplantation.

\section{COMPLICATIONS}

A total of five patients have lost their grafts after hand transplantation. One patient lost his hand as a consequence of intimal hyperplasia in the 
arteries of the graft on day 275 (Louisville) and one patient as a result of progressive rejection of the skin after stopping immunosuppression at 29 months (Lyon) (Kanitakis et al. 2003; Kaufman et al. 2012). Two hands were lost subsequent to arterial thrombosis in Wroclaw (Jablecki 2011). Furthermore, one hand each was reamputated after transplantation in Atlanta and Boston (Pomahac et al. 2012a). Graft survival in hand transplantation 14 years after the first case is currently $82 \%$.

In one case, a venous thrombosis was treated by microsurgical revision (Petruzzo et al. 2010). The thrombosis of an ulnar artery, which required thrombectomy, occurred in another case. There was also one case in which an arteriovenous shunt was observed requiring ligation. Skin necrosis was observed in four cases and required treatment with skin grafts ( $\mathrm{Pe}$ truzzo et al. 2010). A hematoma resulted in wound dehiscence on day 15 after transplantation in one case (Jablecki et al. 2009). In another case, a tenolysis for flexor tendon adhesions was required at 14 months (Schuind et al. 2007). Aseptic necrosis of a hip required treatment with bilateral arthroplasty in one patient (Petruzzo et al. 2010). In one case, Staphylococcus aureus osteomyelitis in the ulna was encountered and treated with antibiotics. CMV infection was reported in a large number of cases. Human papilloma virus infection, herpes simplex infection, fungal infections of the skin and mucosa, and a Clostridium difficile enteritis were reported in a smaller number of patients (Petruzzo et al. 2010). Frequently, transient hyperglycemia, hypertension, and impaired kidney function were observed but reversible with adequate medical treatment (Petruzzo et al. 2010). A basal cell carcinoma of the nose was treated by surgical excision (Landin et al. 2010).

Although psychiatric disorders like depression, fear, or denial of the transplanted hand, may appear especially early after transplantation, the overall adjustment to the new limb has been very good in most cases (Kumnig et al. 2012). In some patients the allografts were fully integrated in cerebral cortex and body image when sensitivity was established. Nevertheless, a suicide attempt was reported in one pa- tient (Schuind et al. 2007), whereas the first recipient of a hand allograft in the recent era of hand transplantation requested reamputation when the hand showed signs of progressive rejection after cessation of immunosuppression (Schneeberger et al. 2011).

One significant problem in some cases after hand transplantation was compliance with medication and the demanding rehabilitation protocol. Although the existing experience with hand transplantation indicates that noncompliance is more common after unilateral than bilateral hand transplantation, this remains to be confirmed in a larger series of patients. A detailed psychological evaluation and risk assessment remains a prerequisite for patients enlisted for hand transplantation.

In face transplantation there have been no documented cases of loss of the allograft secondary to surgical complications such as arterial or venous thrombosis. One patient did require reoperation 3 days postoperatively secondary to a venous thrombosis; however, the anastomosis was revised with salvage of the allograft (Barret et al. 2011). Other documented postoperative surgical complications including ptosis of the eyelids, ectropion, Stenson's duct stenosis, and generalized wound healing problems have all been able to be managed conservatively.

The two most feared complications with immunosuppressive therapy are infections and malignancy. All facial transplantation patients received prophylaxis against opportunistic infections, which typically consists of coverage against herpes simplex (acyclovir), cytomegalovirus (ganciclovir), and Pneumocystis jerovici (trimethoprim-sulfamethoxazole). Despite these measures the majority of patients had at least one episode of an opportunistic bacterial, viral, or fungal infection including cytomegalovirus, Epstein-Barr virus, herpes simplex, herpes zoster, staphylococcal, Pseudomonas, Enterobacter, and Candida infections (Siemionow and Ozturk 2012). There was one death owing to Pseudomonas infection reported in a patient who underwent face as well as bilateral hand transplant (Lantieri et al. 2011). A second death was reported in the patient of Guo et al. (2008) after being noncompliant with immunosup- 
B. Pomahac et al.

pression therapy (Siemionow and Ozturk 2012). Malignancy has been already reported despite the relative infancy of facial transplantation. The first facial transplantation patient developed a cervical carcinoma in situ that was successfully treated with conization (Petruzzo et al. 2012).

\section{OUTLOOK: BASIC AND CLINICAL SCIENCE}

Hand and face allotransplantation are demanding and challenging operations and especially for face transplantation, mock transplantations via cadaveric dissections are recommended before performing the actual operation to ensure optimal outcomes. Several investigators have reported on the use of computerized tomography and cephalometric analysis to plan potential operations (Brown et al. 2012; Caterson et al. 2012). The major hurdle for wider range application of hand and face transplantation, however, remains the reduction or elimination of the need for long-term immunosuppressive treatment. The side effects of immunosuppression hamper the progress in this field as the variety and severity of side effects negatively impact on the risk-benefit balance of such nonlifesaving procedures.

\section{REFERENCES}

Azari KK, Imbriglia JE, Goitz RJ, Shores JT, Balk ML, Brandacher G, Schneeberger S, Gorantla V, Lee WP. 2012. Technical aspects of the recipient operation in hand transplantation. J Reconstr Microsurg 28: 27-34.

Barret JP, Gavalda J, Bueno J, Nuvials X, Pont T, Masnou N, Colomina MJ, Serracanta J, Arno A, Huguet P, et al. 2011. Full face transplant: The first case report. Ann Surg 254: $252-256$.

Baumel JJ. 1974. Trigeminal-facial nerve communications Their function in facial muscle innervation and reinnervation. Arch Otolaryngol 99: 34-44.

Bianchi B, Copelli C, Ferrari S, Ferri A, Bailleul C, Sesenna E. 2010. Facial animation with free-muscle transfer innervated by the masseter motor nerve in unilateral facial paralysis. J Oral Maxillofac Surg 68: 1524-1529.

Brandacher G, Schneeberger S, Margreiter R. 2007. Selection of candidates and waiting list, dealing with the media and the public, setting up a pilot study, clinical trial organisation, staff requisites for hand transplantation: The Innsbruck experience. In Hand transplantation (ed. Lanzetta M, Dubernard JM), pp. 149-157. Springer-Verlag Italia, Milan, Italy.
Brandacher G, Ninkovic M, Piza-Katzer H, Gabl M, Huss H, Rieger M, Schocke M, Egger K, Loescher W, Zelger $\mathrm{B}$, et al. 2009. The Innsbruck hand transplant program: Update at 8 years after the first transplant. Transpl Proc 41: 491-494.

Brandacher G, Lee WP, Schneeberger S. 2012. Minimizing immunosuppression in hand transplantation. Expert Rev Clin Immunol 8: 673-683; quiz 684.

Brown EN, Dorafshar AH, Bojovic B, Christy MR, Borsuk DE, Kelley TN, Shaffer CK, Rodriguez ED. 2012. Total face, double jaw, and tongue transplant simulation: A cadaveric study using computer-assisted techniques. Plast Reconstr Surg 130: 815-823.

Caterson EJ, Diaz-Siso JR, Shetye P, Junker JP, Bueno EM, Soga S, Rybicki FJ, Pomahac B. 2012. Craniofacial principles in face transplantation. J Craniofac Surg 23: $1234-$ 1238.

Cavadas PC, Ibanez J, Thione A. 2012. Surgical aspects of a lower face, mandible, and tongue allotransplantation. J Reconstr Microsurg 28: 43-47.

Cendales LC, Kanitakis J, Schneeberger S, Burns C, Ruiz P, Landin L, Remmelink M, Hewitt CW, Landgren T, Lyons B, et al. 2008. The Banff 2007 working classification of skin-containing composite tissue allograft pathology. Am J Transpl 8: 1396-1400.

Chang G, Pomahac B. 2012. Psychosocial changes 6 months after face transplantation. Psychosomatics 54: 367-371.

Daily Mail Reporter. 2012. Man, 27, who had world's first quadruple limb transplant dies days after operation. Daily Mail Online, February 28.

Devauchelle B, Badet L, Lengele B, Morelon E, Testelin S, Michallet M, D’Hauthuille C, Dubernard JM. 2006. First human face allograft: Early report. Lancet 368: 203-209.

Dorafshar AH, Bojovic B, Christy MR, Borsuk DE, Iliff NT, Brown EN, Shaffer CK, Kelley TN, Kukuruga DL, Barth RN, et al. 2013. Total face, double jaw, and tongue transplantation: An evolutionary concept. Plast Reconstr Surg 131: $241-251$.

Dubernard JM, Lengele B, Morelon E, Testelin S, Badet L, Moure C, Beziat JL, Dakpe S, Kanitakis J, D’Hauthuille C, et al. 2007. Outcomes 18 months after the first human partial face transplantation. N Engl J Med 357: 24512460.

Gilbert R. 1964. Transplant is successful with a cadaver forearm. Med Trib Med News 5: 20-22.

Guo S, Han Y, Zhang X, Lu B, Yi C, Zhang H, Ma X, Wang D, Yang L, Fan X, et al. 2008. Human facial allotransplantation: A 2-year follow-up study. Lancet 372: 631-638.

Hautz T, Brandacher G, Zelger B, Gorantla VS, Lee AW, Pratschke J, Schneeberger S. 2010a. Immunologic aspects and rejection in solid organ versus reconstructive transplantation. Transpl Proc 42: 3347-3353.

Hautz T, Zelger B, Grahammer J, Krapf C, Amberger A, Brandacher G, Landin L, Muller H, Schon MP, Cavadas P, et al. 2010b. Molecular markers and targeted therapy of skin rejection in composite tissue allotransplantation. Am J Transpl 10: 1200-1209.

Hautz T, Engelhardt TO, Weissenbacher A, Kumnig M, Zelger B, Rieger M, Rumpold G, Pierer G, Ninkovic M, Gabl M, et al. 2011. World experience after more than a 
decade of clinical hand transplantation: Update on the Innsbruck program. Hand Clin 27: 423-431, viii.

Hautz T, Wolfram D, Grahammer J, Starzl R, Krapf C, Pratschke J, Lee WP, Brandacher G, Schneeberger S. 2012a. Mechanisms and mediators of inflammation: Potential models for skin rejection and targeted therapy in vascularized composite allotransplantation. Clin Dev Immunol 2012: 757310.

Hautz T, Zelger B, Brandacher G, Mueller H, Grahammer J, Zelger B, Lee A, Cavadas P, Margreiter R, Pratschke J, et al. 2012b. Histopathologic characterization of mild rejection (grade I) in skin biopsies of human hand allografts. Transpl Int 25: 56-63.

Hermanson A, Dalsgaard CJ, Arnander C, Lindblom U. 1987. Sensibility and cutaneous reinnervation in free flaps. Plast Reconstr Surg 79: 422-427.

Hui-Chou HG, Nam AJ, Rodriguez ED. 2010. Clinical facial composite tissue allotransplantation: A review of the first four global experiences and future implications. Plast Reconstr Surg 125: 538-546.

Jablecki J. 2011. World experience after more than a decade of clinical hand transplantation: Update on the Polish program. Hand Clin 27: 433-42, viii.

Jablecki J, Kaczmarzyk L, Patrzalek D, Domanasiewicz A, Chelmonski A. 2009. A detailed comparison of the functional outcome after midforearm replantations versus midforearm transplantation. Transpl Proc 41: 513-516.

Kalache S, Dinavahi R, Pinney S, Mehrotra A, Cunningham MW, Heeger PS. 2011. Anticardiac myosin immunity and chronic allograft vasculopathy in heart transplant recipients. J Immunol 187: 1023-1030.

Kanitakis J, Jullien D, Petruzzo P, Hakim N, Claudy A, Revillard JP, Owen E, Dubernard JM. 2003. Clinicopathologic features of graft rejection of the first human hand allograft. Transplantation 76: 688-693.

Kaufman CL, Ouseph R, Blair B, Kutz JE, Tsai TM, Scheker LR, Tien HY, Moreno R, Ozyurekoglu T, Banegas R, et al. 2012. Graft vasculopathy in clinical hand transplantation. Am J Transpl 12: 1004-1016.

Kerawala CJ, Newlands C, Martin I. 2006. Spontaneous sensory recovery in non-innervated radial forearm flaps used for head and neck reconstruction. Int J Oral Maxillofac Surg 35: 714-717.

Kimata Y, Uchiyama K, Ebihara S, Kishimoto S, Asai M, Saikawa M, Ohyama W, Haneda T, Hayashi R, Onitsuka T, et al. 1999. Comparison of innervated and noninnervated free flaps in oral reconstruction. Plast Reconstr Surg 104: $1307-1313$.

Kumnig M, Jowsey SG, Rumpold G, Weissenbacher A, Hautz T, Engelhardt TO, Brandacher G, Gabl M, Ninkovic M, Rieger M, et al. 2012. The psychological assessment of candidates for reconstructive hand transplantation. Transpl Int 25: 573-585.

Kuriakose MA, Loree TR, Spies A, Meyers S, Hicks WL Jr. 2001. Sensate radial forearm free flaps in tongue reconstruction. Arch Otolaryngol Head Neck Surg 127: 14631466.

Lahteenmaki T, Waris T, Asko-Seljavaara S, Astrand K, Sundell B, Jarvilehto T. 1991. The return of sensitivity to cold, warmth and pain from excessive heat in free microvascular flaps. Scand J Plast Reconstr Surg Hand Surg 25: 143150.
Landin L, Cavadas PC, Ibanez J, Roger I. 2010. Malignant skin tumor in a composite tissue (bilateral hand) allograft recipient. Plast Reconstr Surg 125: 20e-21e.

Landin L, Bonastre J, Casado-Sanchez C, Diez J, Ninkovic M, Lanzetta M, del Bene M, Schneeberger S, Hautz T, Lovic A, et al. 2012. Outcomes with respect to disabilities of the upper limb after hand allograft transplantation: A systematic review. Transpl Int 25: 424-432.

Lantieri L, Meningaud JP, Grimbert P, Bellivier F, Lefaucheur JP, Ortonne N, Benjoar MD, Lang P, Wolkenstein P. 2008. Repair of the lower and middle parts of the face by composite tissue allotransplantation in a patient with massive plexiform neurofibroma: A 1-year follow-up study. Lancet 372: 639-645.

Lantieri L, Hivelin M, Audard V, Benjoar MD, Meningaud JP, Bellivier F, Ortonne N, Lefaucheur JP, Gilton A, Suberbielle C, et al. 2011. Feasibility, reproducibility, risks and benefits of face transplantation: A prospective study of outcomes. Am J Transpl 11: 367-378.

Lee WP, Yaremchuk MJ, Pan YC, Randolph MA, Tan CM, Weiland AJ. 1991. Relative antigenicity of components of a vascularized limb allograft. Plast Reconstr Surg 87: 401-411.

Nanobashvili J, Neumayer C, Fugl A, Punz A, Blumer R, Prager M, Mittlbock M, Gruber H, Polterauer P, Roth E, et al. 2003. Ischemia/reperfusion injury of skeletal muscle: Plasma taurine as a measure of tissue damage. Surgery 133: 91-100.

Petruzzo P, Lanzetta M, Dubernard JM, Landin L, Cavadas P, Margreiter R, Schneeberger S, Breidenbach W, Kaufman C, Jablecki J, et al. 2010. The international registry on hand and composite tissue transplantation. Transplantation 90: 1590-1594.

Petruzzo P, Testelin S, Kanitakis J, Badet L, Lengele B, Girbon JP, Parmentier H, Malcus C, Morelon E, Devauchelle B, et al. 2012. First human face transplantation: 5 years outcomes. Transplantation 93: 236-240.

Pomahac B, Pribaz J, Eriksson E, Annino D, Caterson S, Sampson C, Chun Y, Orgill D, Nowinski D, Tullius SG. 2011. Restoration of facial form and function after severe disfigurement from burn injury by a composite facial allograft. Am J Transpl 11: 386-393.

Pomahac B, Pribaz J, Eriksson E, Bueno EM, Diaz-Siso JR, Rybicki FJ, Annino DJ, Orgill D, Caterson EJ, Caterson SA, et al. 2012a. Three patients with full facial transplantation. N Engl J Med 366: 715-722.

Pomahac B, Pribaz JJ, Bueno EM, Sisk GC, Diaz-Siso JR, Chandawarkar A, Westvik TS, Malin EW, Eriksson E. 2012b. Novel surgical technique for full face transplantation. Plast Reconstr Surg 130: 549-555.

Saavedra AP, Bueno EM, Granter SR, Pomahac B. 2011. Transmission of donor-specific skin condition from donor to recipient of facial allograft. Am J Transpl 11: 1340.

Schneeberger S, Ninkovic M, Gabl M, Ninkovic M, Hussl H, Rieger M, Loescher W, Zelger B, Brandacher G, Bonatti $\mathrm{H}$, et al. 2007. First forearm transplantation: Outcome at 3 years. Am J Transpl 7: 1753-1762.

Schneeberger S, Gorantla VS, Hautz T, Pulikkottil B, Margreiter R, Lee WP. 2009. Immunosuppression and rejection in human hand transplantation. Transpl Proc 41: $472-475$. 
B. Pomahac et al.

Schneeberger S, Landin L, Jableki J, Butler P, Hoehnke C, Brandacher G, Morelon E, ESOT CTA Working Group. 2011. Achievements and challenges in composite tissue allotransplantation. Transpl Int 24: 760-769.

Schneeberger S, Gorantla VS, Brandacher G, Zeevi A, Demetris AJ, Lunz JG, Metes DM, Donnenberg AD, Shores JT, Dimartini AF, et al. 2013. Upper-extremity transplantation using a cell-based protocol to minimize immunosuppression. Ann Surg 257: 345-351.

Schuind F, Abramowicz D, Schneeberger S. 2007. Hand transplantation: The state-of-the-art. J Hand Surg Eur Vol 32: 2-17.

Seetharam A, Tiriveedhi V, Mohanakumar T. 2010. Alloimmunity and autoimmunity in chronic rejection. Curr Opin Organ Transplant 15: 531-536.

Siemionow M, Ozturk C. 2012. Face transplantation: Outcomes, concerns, controversies, and future directions. J Craniofac Surg 23: 254-259.

Siemionow M, Papay F, Alam D, Bernard S, Djohan R, Gordon C, Hendrickson M, Lohman R, Eghtesad B, Coffman K, et al. 2009. Near-total human face transplantation for a severely disfigured patient in the USA. Lancet 374: $203-$ 209.

Siemionow MZ, Papay F, Djohan R, Bernard S, Gordon CR, Alam D, Hendrickson M, Lohman R, Eghtesad B, Fung J.
2010. First U.S. near-total human face transplantation: A paradigm shift for massive complex injuries. Plast Reconstr Surg 125: 111-122.

Siemionow M, Gharb BB, Rampazzo A. 2011. Pathways of sensory recovery after face transplantation. Plast Reconstr Surg 127: 1875-1889.

Soga S, Pomahac B, Wake N, Schultz K, Prior RF, Kumamaru K, Steigner ML, Mitsouras D, Signorelli J, Bueno EM, et al. 2012. CT angiography for surgical planning in face transplantation candidates. AJNR Am J Neuroradiol doi: 10.3174/ajnr.A3268.

Takamatsu A, Harashina T, Inoue T. 1996. Selection of appropriate recipient vessels in difficult, microsurgical head and neck reconstruction. J Reconstr Microsurg 12: 499507; discussion 508-513.

Tohma A, Mine K, Tamatsu Y, Shimada K. 2004. Communication between the buccal nerve $(\mathrm{V})$ and facial nerve (VII) in the human face. Ann Anat 186: 173-178.

van Leeuwen MT, Webster AC, McCredie MR, Stewart JH, McDonald SP, Amin J, Kaldor JM, Chapman JR, Vajdic CM, Grulich AE. 2010. Effect of reduced immunosuppression after kidney transplant failure on risk of cancer: Population based retrospective cohort study. BMJ 340: c570. 


\section{$\& \mathrm{CSH} \&$ Cold Spring Harbor



\section{Facial and Hand Allotransplantation}

Bohdan Pomahac, Ryan M. Gobble and Stefan Schneeberger

Cold Spring Harb Perspect Med 2014; doi: 10.1101/cshperspect.a015651 originally published online January 29, 2014

\section{Subject Collection Transplantation}

Heart Transplantation: Challenges Facing the Field

Makoto Tonsho, Sebastian Michel, Zain Ahmed, et al.

Bioethics of Organ Transplantation Arthur Caplan

Overview of Clinical Lung Transplantation Jonathan C. Yeung and Shaf Keshavjee

Immunological Challenges and Therapies in

Xenotransplantation Marta Vadori and Emanuele Cozzi

Clinical Aspects: Focusing on Key Unique

Organ-Specific Issues of Renal Transplantation Sindhu Chandran and Flavio Vincenti

T-Cell Costimulatory Blockade in Organ

Transplantation

Jonathan S. Maltzman and Laurence A. Turka

Regulatory T-Cell Therapy in Transplantation:

Moving to the Clinic

Qizhi Tang and Jeffrey A. Bluestone

Opportunistic Infections--Coming to the Limits of Immunosuppression?

Jay A. Fishman
Overview of the Indications and Contraindications for Liver Transplantation

Stefan Farkas, Christina Hackl and Hans Jürgen Schlitt

Facial and Hand Allotransplantation Bohdan Pomahac, Ryan M. Gobble and Stefan Schneeberger

Induction of Tolerance through Mixed Chimerism David H. Sachs, Tatsuo Kawai and Megan Sykes

Pancreas Transplantation: Solid Organ and Islet Shruti Mittal, Paul Johnson and Peter Friend

Tolerance--Is It Worth It?

Erik B. Finger, Terry B. Strom and Arthur J. Matas

Lessons and Limits of Mouse Models Anita S. Chong, Maria-Luisa Alegre, Michelle L. Miller, et al.

Effector Mechanisms of Rejection Aurélie Moreau, Emilie Varey, Ignacio Anegon, et al.

The Innate Immune System and Transplantation Conrad A. Farrar, Jerzy W. Kupiec-Weglinski and Steven H. Sacks

For additional articles in this collection, see http://perspectivesinmedicine.cshlp.org/cgi/collection/ 